\title{
Aplikasi Lughat al-Faṣl dalam Pengajaran Bahasa Arab Using Lughat al-Faṣl in Teaching Arabic Language
}

\author{
${ }^{1}$ MOHAMAD ZIYAD BIN MUKHTAR \\ ${ }^{2}$ SAINI AG. DAMIT
}

\begin{abstract}
'Jabatan Bahasa Arab, Institut Pendidikan Guru Kampus Pendidikan Islam, 43650 Bandar Baru Bangi, Selangor. ${ }^{2}$ Fakulti Kemanusiaan, Seni dan Warisan, Universiti Malaysia Sabah, Jalan UMS, 88400 Kota Kinabalu. saini@ums.edu.my

Diterima: 28 September 2017 / Dibaiki: 2 November 2017
\end{abstract}

Abstrak Penggunaan bahasa Arab dalam proses pengajaran adalah penting bagi memahirkan murid berbahasa. Persekitaran berkomunikasi bahasa Arab yang baik boleh diwujudkan melalui aplikasi Lughat al-Fașl secara ekspresif dan berkesan. Lughat al-Fașl ialah perkataan atau ungkapan mudah yang mengandungi arahan, soalan, peneguhan dan larangan dalam Bahasa Arab yang selalu digunakan oleh guru sebagai bahasa perantaraan menyampaikan isi kandungan pelajaran ketika berinteraksi dengan murid dalam kelas. Kajian ini bertujuan mengenal pasti jenis-jenis Lughat alFașl yang digunakan guru dan halangan yang dihadapi dalam mengaplikasi Lughat al-Faṣl dalam PdP Bahasa Arab di sekolah rendah. Di samping itu, kajian ini juga mengetengahkan beberapa langkah dan cadangan untuk memperbaiki amalan Lughat al-Faṣl guru dan mengatasi halangan interaksi lisan tersebut. Kajian ini merupakan kajian kualitatif dengan menggunakan pemerhatian dan protokol temu bual sebagai instrumen kajian. Peserta kajian terdiri daripada empat orang guru bahasa Arab sekolah rendah. Pemerhatian ke atas pengajaran guru dilaksanakan bagi mengenal pasti jenis Lughat al-Faṣl yang digunakan guru. Manakala temu bual pula dijalankan bagi mendapatkan maklumat yang berkaitan dengan halangan aplikasi Lughat al-Faṣl semasa melaksanakan PdP. Penganalisisan data dilakukan dengan membuat transkrip pengajaran dan temu bual berdasarkan rakaman yang dibuat. Hasil kajian mendapati terdapat tujuh jenis Lughat al-Faṣl yang digunakan guru dan mengenal pasti beberapa halangan yang dihadapi oleh guru ketika mengaplikasikan Lughat al-Faṣl dalam PdP Bahasa Arab termasuk halangan dari segi personaliti dan sikap guru, kelayakan guru dan persekitaran komunikasi bahasa Arab. Dapatan dari pemerhatian dan temu bual juga telah mencadangkan beberapa cara penyelesaian untuk guru mengatasi semua halangan tersebut.

Kata Kunci: Lughaț al-Faṣl, Interaksi Lisan, Jenis LF, halangan, cadangan. 
Abstract The use of the Arabic language in the teaching process is important for students to master the language. The Arabic language communication environment can be created through the application of Lughat al-Fașl as expressively and effectively. Lughat al-Fașl, is a simple word or phrase containing instructions, questions, reinforcements and prohibitions in Arabic that are often used by teachers as a medium to deliver lesson while interacting with students in the classroom. This study aims to identify the type of LF used by the teachers and the barrier faced by the teachers during the use of LF in Arabic Language lesson in primary schools. In addition, several steps and suggestions were highlighted to improve the teacher's LF in order to overcome the barriers. This study is a qualitative study using observation and interview protocol as a research instrument. The participants consisted of four primary schools Arabic teachers. Observation of teaching is carried out to identify the types of LF while the interviews were conducted to obtain information related to $L F$ and the barriers during the implementation of the teaching and learning. Data is analyzed by making transcripts of the teaching and interviews based on the recording made. The findings showed that there are seven types of phrases in LF used by the teachers as well as a number of obstacles experienced by teachers when applying the LF in the teaching and learning of Arabic language. The barriers were the personalities and attitudes of teachers, teacher's qualifications and also the Arabic communication environment. The findings from observations and interviews have also suggested a number of solutions for teachers to overcome all these obstacles.

Keywords: Lughat al-Faṣl, Speech Interaction, LF Type, obstacles, solutions.

\section{PENDAHULUAN}

Taraf keberkesanan pembelajaran bahasa asing di dalam kelas bergantung pada beberapa faktor utamanya yang berpusat pada guru. Fungsi guru sebagai fasilitator, inspirator, motivator, dan direktor pembelajaran memainkan peranan penting dalam mempersiapkan pembelajaran yang berkesan. Sesungguhnya, proses PdP bahasa Arab di kelas-kelas akan memberikan kontribusi terhadap keberhasilan menguasai bahasa asing 
apabila diselenggarakan dengan baik dan sempurna. Guru bahasa Arab yang baik seharusnya memiliki banyak ciri. Antaranya ialah suara yang jelas, persediaan psikologi dan pengetahuan, perancangan pengajaran yang rapi, kreatif, bersemangat dan bijak membangkitkan motivasi, penampilan yang menarik dan sebagainya (Mohd Rosdi Ismail \& Mat Taib Pa, 2007:12).

Sulaiman Md. Yassin et al. (2007) menyatakan bahawa setiap guru perlu mahir dalam berkomunikasi, khususnya di dalam bilik darjah. Sekiranya guru tidak mahir dalam berkomunikasi dengan pelajar-pelajarnya semasa mengajar, hal ini akan menyebabkan pengajarannya sukar difahami oleh pelajar. Rosni Samah (2009) pula menyatakan bahawa proses pembelajaran menggunakan bahasa Arab dapat membantu penguasaan murid dan kelas yang berinteraksi dalam bahasa Arab dari dua hala, guru dan murid lebih membantu dalam penguasaan bahasa Arab. Keberkesanan pengajaran guru berkait rapat dengan faktor komunikasi yang baik daripada guru tersebut.

Muhammed Barakat (1984:137) berpendapat bahawa bahasa guru adalah agen perhubungan yang paling penting dan dominan dalam interaksi di bilik darjah. Justeru, selain menguasai ilmu, guru perlu menyampaikan isi kandungan pelajaran dengan bahasa yang boleh difahami oleh golongan sasaran iaitu pelajar. Bukan itu sahaja, para pelajar juga sepatutnya mempunyai kesediaan untuk belajar dengan mengetahui perbendaharaan kata bahasa gurunya kerana interaksi dua hala ini akan banyak membantu memahami isi kandungan pelajaran.

Matlamat pengajaran bahasa Arab di Malaysia boleh dilihat dalam Dokumen Standard Kurikulum (DSK) Bahasa Arab KSSR dan Dokumen Standard Kurikulum dan Pentaksiran (DSKP) Bahasa Arab KSSR (Bahagian Pembangunan Kurikulum, 2010) sepertimana berikut;

\footnotetext{
"Pengajaran dan pembelajaran bahasa Arab di peringkat sekolah rendah bermatlamat untuk menanam minat murid mempelajari asas-asas bahasa Arab bagi menguasai kemahiran berbahasa Arab di samping membolehkan murid berkomunikasi menggunakan ayatayat mudah".
} 
Salah satu teknik komunikasi berkesan yang boleh diaplikasi oleh guru dalam pembelajaran bahasa Arab ialah penggunaan Lughat al-Faṣl atau bahasa pengendalian kelas.

\section{OBJEKTIF KAJIAN}

1. Mengenal pasti jenis Lughat al-Faṣl yang digunakan oleh guru dalam pengajaran bahasa Arab.

2. Mengenal pasti halangan yang dihadapi oleh guru menggunakan Lughat al-Faṣl dalam pengajaran bahasa Arab.

3. Mencadangkan langkah-langkah yang boleh diambil oleh guru bahasa Arab dalam menambah baik penggunaan Lughat al-Faṣl semasa pengajaran bahasa Arab.

\section{METODOLOGI KAJIAN}

Kajian ini menggunakan kaedah kualitatif yang menggunakan reka bentuk satu kes pelbagai tempat. Kes yang dimaksudkan dalam kajian ini ialah berasaskan halangan interaksi lisan guru menggunakan Lughat al-Faṣl semasa pengajaran bahasa Arab. Sementara itu, tempat kajian ialah di empat buah sekolah di sekitar negeri Perak.

Satu pemerhatian ke atas sesi pengajaran guru dijalankan untuk mendapatkan data tentang jenis-jenis Lughat al-Fașl yang digunakan guru. Protokol temu bual dilaksanakan bagi mencungkil halangan interaksi lisan guru menggunakan Lughat al-Faṣl. Semua data yang dikumpulkan ini memenuhi piawaian kajian yang menggunakan pendekatan kualitatif, bermula daripada awal penentuan topik dan kaedah, pemilihan peserta, kutipan data sehinggalah analisis dapatan yang sentiasa mengambil kira kesahan dari segi luaran dan dalaman serta kebolehpercayaan yang dipayungi oleh etika kajian (Miles \& Huberman, 1994). 


\section{RESPONDEN KAJIAN}

Dalam kajian ini, peserta kajian yang dipilih terdiri daripada empat orang guru yang mengajar bahasa Arab sekolah rendah di negeri Perak. Spindler (1982) menganggap peserta kajian sebagai pakar tentang apa yang ingin diselidiki oleh pengkaji. Pemilihan peserta kajian ini adalah berdasarkan empat kriteria penting, iaitu pengalaman mengajar, mengetahui dengan baik aplikasi interaksi lisan dalam pengajaran bahasa Arab, terdapat cadangan dan sokongan pentadbir sekolah dan kesanggupan guru tersebut menjadi peserta kajian seperti yang dicadangkan oleh Spradly (1980) dan Jogersen (1989) yang menggunakan teknik 'judgement sampling' .

Kriteria pertama iaitu dipilih daripada kalangan Guru Bahasa Arab (GBA) yang mengajar Bahasa Arab KSSR. Dalam hal ini, pengkaji turut memastikan agar guru yang terpilih sebagai peserta kajian adalah guru yang berpengalaman mengajar bahasa Arab, terutamanya bahasa Arab KSSR. Keempat-empat peserta kajian yang dipilih memenuhi kriteria ini kerana ketika kajian ini dijalankan, kesemua mereka telah mengajar mata pelajaran bahasa Arab lebih dari enam tahun. Malahan, mereka juga telah dikenal pasti pernah terlibat menjadi Jurulatih Utama bahasa Arab Negeri Perak dan banyak membantu pihak Jabatan Pendidikan Negeri Perak melatih guru-guru bahasa Arab, khususnya dalam bidang pedagogi dan kurikulum.

\section{KEPENTINGAN KAJIAN}

Kajian ini sangat penting bagi mengkaji jenis Lughat al-Faṣl yang sering digunakan oleh guru dan halangan yang dihadapi terhadap PdP bahasa Arab melalui penggunaan Lughat al-Fașl dan seterusnya mencadangkan langkah penambahbaikan bagi aplikasi Lughat al-Fașl. Interaksi dua hala yang aktif antara guru dan murid mesti ditekankan semasa berlangsungnya proses pengajaran. Objektif pengajaran tidak akan tercapai jika interaksi dua hala yang efisien tidak berlaku. Sekiranya guru dapat mengaplikasi Lughat alFașl secara efisien, maka murid juga akan lebih berminat dan mempunyai motivasi yang tinggi untuk mempelajari bahasa Arab. 
Dapatan kajian ini boleh digunakan oleh Bahagian Pendidikan Islam (BPI) dan Bahagian Pembangunan Kurikulum (BPK) di Kementerian Pelajaran Malaysia, Jabatan Pelajaran Negeri (JPN), Pejabat Pelajaran Daerah (PPD), Institut Pengajian Tinggi (IPT), Institut Pendidikan Guru (IPG) atau sekolah untuk meningkatkan lagi kualiti pengajaran dan pembelajaran bahasa Arab melalui pembinaan modul-modul pengajaran yang lebih efektif, terutamanya yang berkait dengan komunikasi dalam kelas. Hasil kajian ini juga diharap dapat digunakan oleh pihak Kementerian Pelajaran Malaysia untuk mengenal pasti punca masalah sebahagian guruguru bahasa Arab yang tidak dapat berkomunikasi dalam bahasa Arab dengan baik, khususnya ketika melaksanakan PdP di dalam kelas. Justeru, perancangan dan langkah yang relevan perlu diambil segera untuk mengatasi masalah ketidakmampuan guru mengajar bahasa Arab dengan menganjurkan kursus-kursus pemantapan komunikasi bahasa Arab secara berkala sama ada di negara atau luar negara.

Dapatan kajian ini akan memberi implikasi kepada gaya pengajaran guru, iaitu sejauh mana pertolongan, latihan dan peneguhan pembelajaran sesuai dengan keperluan pelajar (Bloom 1976, dlm. Misnan Jemali, 1999: 26). Dalam konteks ini, komunikasi guru dianggap menjadi penggerak utama terhadap maklum balas pelajar di dalam kelas yang lebih banyak bertunjangkan interaksi lisan. Amalan Lughat al-Faṣl yang baik dan berkesan mampu menghasilkan senario pembelajaran bahasa Arab yang sebenar dan menyeronokkan. Selain itu, ia juga akan menyediakan pengalaman pembelajaran yang akan diingati oleh murid sepanjang hayatnya. Pembelajaran gaya pengalaman yang konkrit adalah lebih efektif dan meninggalkan kesan yang lebih lama pada diri murid berbanding gaya tradisional atau cara abstrak yang berbentuk kuliah (Rohaila Yusof et al., 2005). Oleh itu, kajian-kajian akademik yang seumpama dengan kajian ini penting dijalankan untuk menjadi garis panduan kepada pelaksanaan Lughat al-Faṣl dalam pengajaran bahasa Arab yang lebih baik dan berkesan. 


\section{TINJAUAN LITERATUR}

Kurikulum Bahasa Arab Komunikasi Sekolah Rendah menuntut guru Bahasa Arab mengajar subjek ini menggunakan bahasa tersebut di dalam bilik darjah sebagai bahasa pengendalian kelas agar pelajar dapat berkomunikasi dengan baik. Tanggungjawab ini bukanlah satu perkara yang mudah kerana mereka terpaksa mengajar pelajar yang kurang mahir berbahasa. Lebih-lebih lagi, ada antara guru yang tidak fasih berbahasa Arab. Dari sudut teori, interaksi bermaksud satu proses penyampaian maklumat dan pengalaman antara seorang dengan yang lain atau antara sekumpulan manusia berdasarkan peraturan tertentu yang digambarkan melalui simbol, saluran atau kaedah tertentu. Interaksi menghubungkan antara pihak penyampai (sumber) maklumat dengan penerima maklumat. Proses ini adalah satu bentuk sosialisasi masyarakat dalam peradaban manusia dan merupakan satu kesinambungan tamadun (Ahmad Muhammed Ma'tuk, 1996: 71).

Interaksi murid dan guru dalam bilik darjah adalah terhad. Oleh hal yang demikian, segala maklum balas yang berlaku antara dua pihak berlaku secara spontan. Ia seolah-olah tidak langsung memberi kesempatan untuk merancang dan berfikir. Justeru, guru perlu lebih kreatif dan inovatif dalam mengemudi perjalanan PdP. Guru juga perlu sabar, bijaksana, cekap dan optimis dalam menghadapi sesuatu situasi yang mungkin berlaku secara tiba-tiba. Menurut Jefridin (2010: 1), aktiviti komunikasi dapat berjalan lancar menerusi kebijaksanaan penutur dan pendengar dalam memberi maklum balas, sama ada secara lisan (verbal) atau bukan lisan (non-verbal).

\section{Definisi Lughat al-Faṣl}

Secara umumnya, Lughat al-Fașl ialah ayat-ayat pendek, mudah dan ringkas yang biasa digunakan di dalam kelas. Biasanya, ayat yang digunakan adalah ayat perintah dan suruhan, ayat larangan dan kata peneguhan positif (Firdaus \& Aminuddin, 2014). Dari segi bahasa, perkataan Lughat

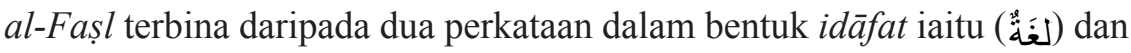
( الفَصْلِ ( ). Apabila dua perkataan ini digabungkan, ia akan menjadi Lughat al-Faṣl (لغَةُ الفَصْنِ yang membawa maksud bahasa kelas. Pengkaji lebih 
cenderung mendefinisikannya sebagai bahasa pengendalian kelas seperti yang digunakan oleh Azhar (2007).

Modul pengajaran Diploma Perguruan Lepas Ijazah (DPLI) yang dikeluarkan oleh Institut Pendidikan Guru Malaysia (2013) ada memasukkan satu topik khas tentang Lughat al-Fașl dengan menyatakan kepentingan Lughat al-Faṣl berserta beberapa contoh ungkapan atau ayat bahasa pengendalian kelas. Ia ditakrifkan seperti yang berikut:

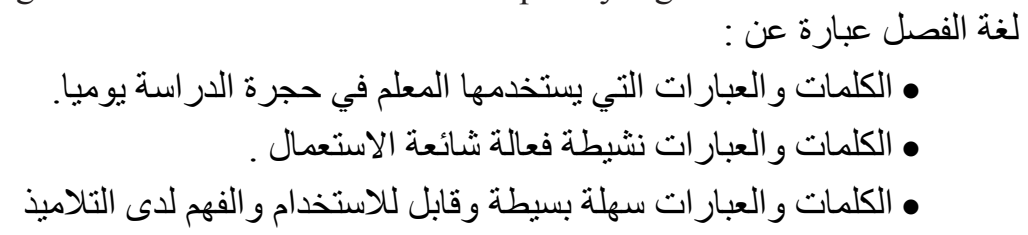

"Bahasa pengendalian kelas adalah perkataan atau ayat yang digunakan oleh guru setiap hari di dalam bilik darjah. Perkataan atau ayat itu sangat berfungsi, luas penggunaannya, mudah, ringkas dan sesuai digunakan dalam kalangan pelajar".

Michelle Louwerse (2001) pula mendefinisikan classroom language sebagai;

"Bahasa bilik darjah adalah sebuah koleksi frasa yang digunakan untuk komunikasi di antara guru dan pelajar, bermula dari "Buka buku anda halaman 15 " hinggalah "Boleh saya pergi ke bilik air?". Walaupun penekanan diletakkan terutamanya kepada bahasa sasaran, bahasa bilik darjah juga boleh menjadi cara yang paling baik untuk mempromosikan Bahasa Inggeris sebagai komunikasi sebenar, penglibatan pelajar dalam PdP, dan satu bahasa yang aktif tentang kemahiran belajar."

Di samping definisi di atas, Firdaus et al. (2014) menjelaskan bahawa Lughat al-Fașl ialah ayat-ayat pendek, mudah dan ringkas yang biasa digunakan dalam kelas. Biasanya, ayat yang digunakan adalah ayat perintah dan suruhan, ayat larangan dan kata peneguhan positif. Sekiranya ayat-ayat ini sering digunakan semasa PdP, maka kebolehan untuk memahami dan menguasai bahasa Arab akan menjadi lebih mudah bagi murid sekolah rendah. Ia juga dapat menanam minat mereka mempelajari bahasa Arab dengan membolehkan mereka mampu berkomunikasi dengan mudah dan betul. 
Menurut Mior Syazril (2015), istilah Lughațal-Faṣl ini lebih hampir dengan guru-guru bahasa Arab yang mengajar mata pelajaran bahasa Arab, sama ada di Malaysia mahupun di mana sahaja. Istilah ini meliputi pelbagai aspek dalam pengajaran guru. Contohnya, kaedah bertanya kepada murid dalam bahasa Arab, membetulkan kesilapan murid dalam bahasa Arab, mengemukakan soalan dalam bahasa dan tidak ketinggalan juga memberi peneguhan kepada murid dalam bahasa Arab. Secara umumnya, fokus Lughat al-Fașl ini adalah penggunaan bahasa Arab sebagai satu-satunya bahasa dalam menyampaikan pengajaran di dalam bilik darjah (Bahagian Pembangunan Kurikulum, 2010).

Penggunaan istilah 'Bahasa Kelas' sebagai terjemahan spontan bagi istilah Lughat al-Faṣl tidak digunakan dalam perbahasannya secara akademik. Namun, apa yang telah ditulis oleh Robert J. Marzano et al. (2001) dalam "Classroom Instructional That Work" adalah lebih menyamai dengan apa yang terkandung dalam konsep Lughat al-Faṣl ini.

Justeru, perkara yang dimaksudkan sebagai Lughat al-Fașl dalam kajian ini ialah perkataan atau ungkapan mudah dalam Bahasa Arab yang selalu digunakan oleh guru sebagai bahasa perantaraan menyampaikan isi kandungan pelajaran ketika berinteraksi dengan pelajar dalam kelas. Perkataan atau ungkapan ini boleh diucapkan oleh guru, sama ada dalam bentuk arahan, penyoalan, pujian atau larangan.

\section{Kepentingan Lughaț al-Faṣl}

Kebanyakan sarjana yang mengkaji berkaitan pertuturan bahasa asing dalam kalangan pelajar mendapati beberapa permasalahan yang timbul adalah disebabkan beberapa faktor termasuk kekurangan kosa kata (Gan, 2012) dan takut pada kesalahan struktur bahasa atau penggunaan bahasa (Tanveer, 2007). Selain itu, faktor motivasi diri juga akan turut menjejaskan penguasaan sesuatu bahasa terutama bahasa asing. Kesan daripada kurangnya motivasi, keyakinan diri dan perasaan malu untuk bertutur dalam bahasa asing akan menjadikan pelajar kurang mempunyai inisiatif untuk mempelbagaikan strategi komunikasi (Rosni, 2013). 
Salah satu kaedah untuk mendedahkan dan memantapkan murid dengan penguasaan kemahiran berbahasa Arab adalah melalui Lughat alFașl. Pemerhatian yang dibuat oleh Aminudin (2014) ke atas guru j-QAF semasa praktikum di IPG Kampus Ilmu Khas mendapati kebanyakan mereka tidak dapat bertutur dengan baik kerana tidak menguasai Lughat al-Fașl. Masalah ini bukan sahaja akan memberi impak yang negatif kepada sesi PdP, malah akan menutup minat murid mempelajari bahasa Arab. Sepatutnya, guru tersebut perlu melatih mereka berkomunikasi dalam bahasa Arab dengan mudah dan betul. Penggunaan Lughat al-Faṣl yang merangkumi ayat atau ungkapan yang mudah, ringkas, mudah difahami dan selalu digunakan di dalam kelas dapat membantu menjayakan pengajaran guru dengan lebih berkesan.

Proses pengajaran yang berpusat kepada guru yang menjadikan guru melaksanakan semua tugas pengajaran dari awal kelas sehinggalah tamat sepatutnya boleh ditukar menjadi pengajaran berpusatkan pelajar. Guru menjadi penggerak utama dalam proses tersebut yang menggunakan Lughat al-Faṣl sebagai bahasa perantara. Tanpa guru, proses pengajaran tidak akan berjaya. Hasil daripada proses pengajaran yang berpusatkan guru semata-mata akan menyebabkan pelajar menjadi lembap dan tidak aktif, khususnya untuk menyuarakan pendapat dan pandangan (Rosni bin Samah, 2007).

Apabila guru dapat mengaplikasikan Lughat al-Faṣl pada setiap kali PdP berlangsung, murid sudah tentu tidak lagi bersifat pasif dan hanya menunggu serta mendengar apa yang disampaikan oleh guru. Mereka akan bermotivasi dan terangsang untuk berinteraksi dengan penggunaan bahasa pengendalian kelas yang mudah difahami. Di samping itu, guru tidak perlu menyusun ayat yang sukar ketika memberi arahan, sebaliknya hanya perlu

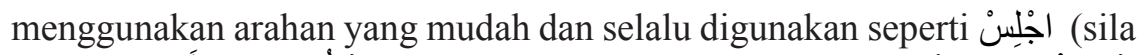

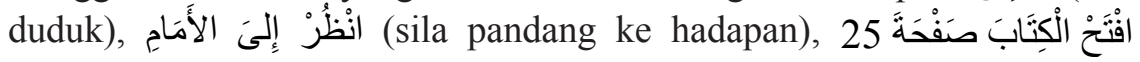
(sila buka buku muka surat 25).

Sebenarnya, proses pengajaran yang berpusatkan kepada pelajar boleh dilaksanakan dengan bimbingan daripada guru. Murid harus diberi peluang untuk berinteraksi dan mengemukakan pandangan. Mereka juga 
perlu diajukan dengan beberapa soalan yang berkaitan dengan subjek yang diajar. Guru hanya berperanan sebagai fasilitator sahaja di dalam kelas. Pada ketika inilah, Lughat al-Faṣl menjadi agen perubahan pada aktiviti kelas. Justeru, guru sangat perlu menguasai Lughat al-Fașl dan menjadikannya sebagai bahasa perantara utama ketika berinteraksi di kelas. Dengan adanya perubahan pada aspek pengajaran ini, sikap pelajar akan dapat dibentuk dan Kemahiran Insaniah mereka akan dapat dibina dan ditingkatkan (Rosni bin Samah, 2007). Terdapat ramai murid yang ingin berkomunikasi dalam bahasa Arab tetapi tidak tahu apa yang perlu dituturkan. Sepatutnya Lughat al-Faṣl yang digunakan oleh guru akan dapat membantu murid menguasai kemahiran mendengar dan bertutur mereka.

Usaha menanam dan memupuk minat murid mempelajari bahasa Arab sangat perlu dimulakan semenjak awal persekolahan mereka. Lughat al-Faṣl adalah merujuk kepada bahasa yang digunakan oleh guru ketika menjalankan proses pengajaran dan pembelajaran, sama ada di dalam kelas atau di luar kelas. Antara objektif utama pembelajaran Bahasa Arab dalam KSSR (KPM, 2010) ialah:

- Mendengar bunyi huruf, perkataan, frasa dan teks.

- Menyebut huruf dan perkataan dengan betul.

- $\quad$ Bertutur dalam pelbagai situasi.

- Membaca perkataan, frasa, teks dengan betul.

- Mengaplikasikan asas tatabahasa Bahasa Arab dalam pertuturan dan penulisan.

- Menghafaz kata-kata hikmat dan peribahasa terpilih dan memperdengarkannya.

- Menggunakan Bahasa Arab standard dalam pertuturan dan penulisan.

Mior Syazril (2015) ada membuat kajian untuk melihat senario sebenar pelaksanaan amalan Lughat al-Faṣl dalam kalangan guru bahasa Arab sekolah rendah. Antara persoalan yang dikaji adalah lebih menjurus kepada jenis penggunaan, cara penyampaian, masalah yang dihadapi dan penambahbaikan sebagai garis panduan kepada amalan Lughațal-Faṣl ini oleh guru-guru bahasa Arab sekolah rendah yang lain. Keputusan yang diperoleh menunjukkan terdapat enam jenis amalan Lughat al-Faṣl yang 
dominan dan diamalkan oleh responden tersebut ketika aktiviti pengajaran mereka di dalam bilik darjah. Beberapa masalah yang timbul berkaitan pelaksanaan amalan ini juga diketengahkan oleh responden dalam kajian ini dengan memberikan alternatif penyelesaiannya.

Mohamad Ziyad dan Saini (2015) telah menjalankan kajian berkenaan amalan Lughat al-Faṣl dalam kalangan guru pelatih DPLI j-QAF di IPG. Dari segi kesediaan guru pelatih menggunakan bahasa Arab sepenuhnya dalam pengajaran, dapatan menunjukkan mereka mempunyai kesediaan yang tinggi untuk mengaplikasikan Lughat al-Faṣl dalam pengajaran. Mereka sentiasa berusaha mencuba menggunakan ungkapan-ungkapan bahasa Arab dalam menyampaikan isi kandungan pelajaran melalui ungkapan yang mudah Lughat al-Fașl. Oleh kerana majoriti responden beranggapan bahawa penggunaan Lughat al-Faṣl yang berkesan oleh guru dapat menghidupkan suasana pembelajaran yang kondusif, maka mereka sentiasa meminta nasihat daripada pensyarah pembimbing tentang penggunaan Lughat al-Fașl, terutama dalam aspek kawalan kelas.

Dalam kajian itu juga, didapati kebanyakan mereka dapat melatih pelajar memahami Lughat al-Faṣl dalam masa kurang dari dua bulan dengan memperkenalkan tiga hingga lima ungkapan baharu dalam tempoh sebulan. Situasi ni menunjukkan mereka bekerja keras untuk memahamkan pelajar tentang ungkapan Lughat al-Faṣl tersebut kerana ia sangat membantu melancarkan proses PdP, terutama ketika menjalani latihan mengajar (praktikum). Satu perkara lagi yang perlu dinyatakan di sini ialah tentang langkah yang kerap diambil oleh guru pelatih ketika mengajar sekiranya pelajar tidak memahami pertuturan atau ungkapan yang dilontarkan guru. Hampir kesemua mereka memilih untuk melakonkannya dengan pergerakan badan (body language) atau mengulang ungkapan berserta aksi sehingga difahami pelajar. Keadaan ini menunjukkan bahawa aplikasi Lughațal-Faṣl dalam pengajaran sangat perlu dibantu menggunakan bahasa badan (body language) supaya para pelajar dapat memahaminya dengan lebih cepat dan bukannya terus menterjemah perkataan tersebut ke bahasa Melayu. Guru pelatih ini sedar bahawa kaedah terjemahan tidak akan membantu pelajar menguasai ilmu yang mereka belajar dengan sendiri dan juga tidak membantu mereka untuk aktif dan berinteraksi dalam kelas (Rosni, 2012: 293). 


\section{DAPATAN KAJIAN}

\section{Jenis-jenis Lughaț al-Faṣl}

Melalui pemerhatian pengajaran yang dijalankan, terdapat tujuh jenis Lughat al-Faṣl yang digunakan oleh guru iaitu: (a) ucapan salam dan selamat, (b) ungkapan mudah harian, (c) pujian dan peneguhan, (d) arahan dan suruhan (e) larangan (f) penyoalan dan (g) membetulkan kesilapan Contoh-contoh bagi setiap jenis adalah seperti berikut:

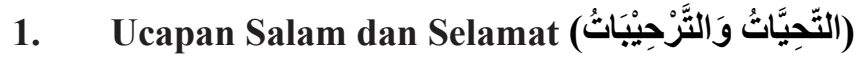

\begin{tabular}{|c|c|}
\hline BAHASA MELAYU & اللغة العربية \\
\hline Assalamualaikum & 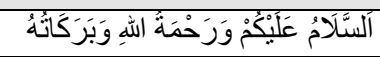 \\
\hline Waalaikumussalam & 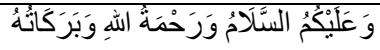 \\
\hline Selamat Pagi & صَبَاحَ الْخَيْرِ \\
\hline Selamat Pagi & صَبَاحَ النّورِ \\
\hline Apa khabar? & كَيْفَ حَالَكَْْ \\
\hline Bagaimana kesihatan kamu? & 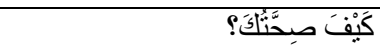 \\
\hline Alhamdulillah, saya dalam keadaan baik & أَحَمْنُ لَه، أَنَا بِخَيْرِ \\
\hline Kamu pula bagaimana? & وَكَيْفَ أَنْتَ؟ \\
\hline Alhamdulillah, saya juga dalam keadaan baik & 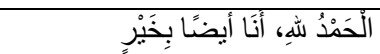 \\
\hline Selamat Datang! & مَزْحَبـا بِكَ \\
\hline Selamat Datang & 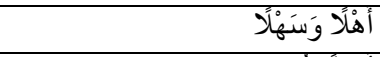 \\
\hline Selamat Datang! (jawapan) & أهْلاًُ بِكْْ \\
\hline Selamat Petang! & مَســاءَ الخَيْرِ \\
\hline Selamat Petang! (Jawapan) & مَســاءَ النُّورِ \\
\hline Terima kasih! & شُكُرَا جَزِِْلْا \\
\hline Sama-sama! & عَفًْا \\
\hline Jumpa Lagi! & إلِىَ اللَّقَاءِ \\
\hline Selamat Jalan! & مَعَع السَّلامَةِة \\
\hline Semoga dalam lindungan Allah! & فِي أمَانِ اللهِ \\
\hline
\end{tabular}




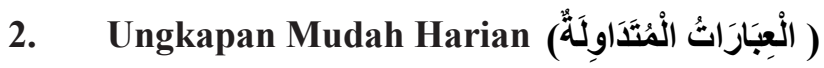

\begin{tabular}{|c|c|}
\hline BAHASA MELAYU & اللغة العربية \\
\hline $\begin{array}{l}\text { Maafkan saya, apa topik kita sekarang/ } \\
\text { hari ini? }\end{array}$ & 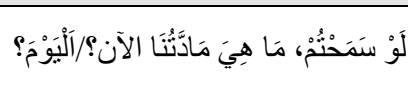 \\
\hline Hari ini hari apa? & 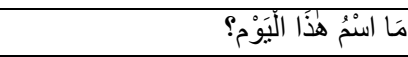 \\
\hline Apa tarikh hari ini? & 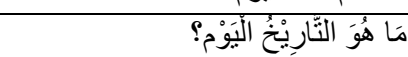 \\
\hline Siapa ketua kelas? & 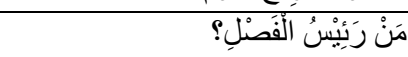 \\
\hline Siapa yang tidak hadir hari ini? & 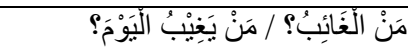 \\
\hline $\begin{array}{l}\text { Muhammad, kenapa kamu tidak hadir } \\
\text { kelmarin? }\end{array}$ & يَا مُحَدَدُ، لِمَاذَا لَمْ تَخْضُرْ أَمْس؟ \\
\hline Saya mahu... & أَنَا أرِيْدُ .... \\
\hline Siapa nama kamu? & مَا اسنمُكُكَْْ \\
\hline Nama saya... & اسنمِيْ ..... \\
\hline Adakah kamu seorang pelajar? & هَلْ أنْتَ طَالِبِّْ \\
\hline Di mana kamu tinggal? & 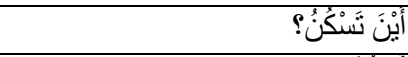 \\
\hline Saya tinggal di... & أَسْكُنُ في .... \\
\hline Siapa yang tahu jawapan? & مَنْ يَعْرِقُ الْإِجَابَةُّ \\
\hline Semua sekali... & 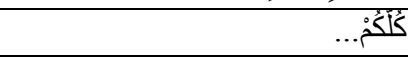 \\
\hline $\begin{array}{l}\text { Saya mahu anda semua buat latihan } \\
\text { nombor } 6\end{array}$ & 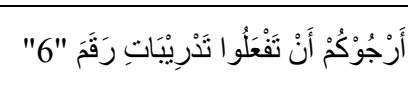 \\
\hline Adakah anda bersedia? & 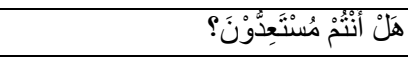 \\
\hline
\end{tabular}




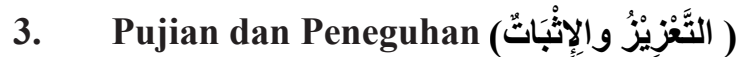

\begin{tabular}{|c|c|}
\hline BAHASA MELAYU & اللغة العربية \\
\hline Cemerlang! Kamu hebat! & 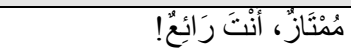 \\
\hline $\begin{array}{l}\text { Tulisan kamu cantik, seperti kamu } \\
\text { juga! }\end{array}$ & 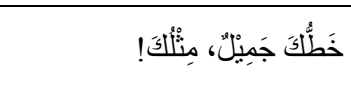 \\
\hline Kamu pelajar yang rajin! & 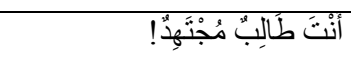 \\
\hline $\begin{array}{l}\text { Saya sayang kamu semua, wahai } \\
\text { anak-anakku! }\end{array}$ & 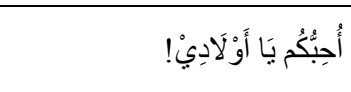 \\
\hline Cantik, wahai pahlawan! & جَمِيلٌ يَا بَطُلَ! \\
\hline $\begin{array}{l}\text { Hadiah ini sebagai penghargaan pada } \\
\text { kamu! }\end{array}$ & هَذْهِ هَدِيَّة تَعْزِيزًا لَكَكَ! \\
\hline Cemerlang! Saya beri tiga bintang! & 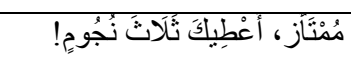 \\
\hline $\begin{array}{l}\text { Jawapan ini sangat mengagumkan } \\
\text { saya! }\end{array}$ & تُعْجِبُنْيْ هُذِهِ الْإِجَابَةُ \\
\hline $\begin{array}{l}\text { Kamu sangat bagus! Semoga Allah } \\
\text { memberkatinya! }\end{array}$ & أَحْسَنْنَ، وَبَارَكَكَ اللهُ فِيكَ \\
\hline Tahniah! & مُبَارَكَكُ! \\
\hline Terbaik! (manis) & حُلوَّ" \\
\hline Betul! & صَحِيحُ! \\
\hline Hebat! & عَظِيمُ! \\
\hline Bijak! Genius! & 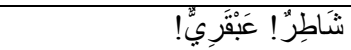 \\
\hline Kamu sangat bagus! & أحْسنْتَ! \\
\hline Pandai! & ذَكِيٌّ! \\
\hline Tersusun! & مُرَتبّبٌ! \\
\hline Cemerlang! & مُمْنَّازْ! \\
\hline Mengagumkan! & رَائعُ! \\
\hline
\end{tabular}




\section{Arahan dan Suruhan (الأََامِرُ وَالطَََّبُ )}

\begin{tabular}{|c|c|}
\hline BAHASA MELAYU & اللغة العربية \\
\hline Sila duduk! & 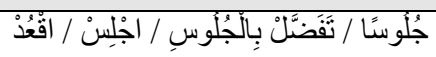 \\
\hline Sila berdiri! & 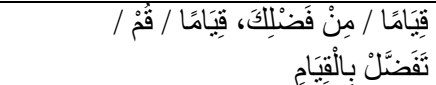 \\
\hline Sila datang ke hadapan! & 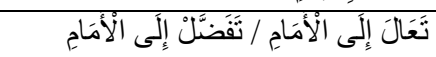 \\
\hline Tolong bersihkan papan putih! & 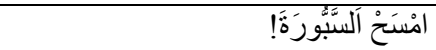 \\
\hline $\begin{array}{l}\text { Sila lihat ke sini! } \\
\text { Sila lihat ke papan putih! }\end{array}$ & 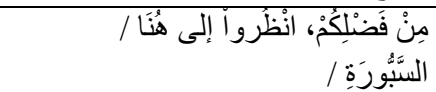 \\
\hline $\begin{array}{l}\text { Sila lihat ke arah saya! } \\
\text { Sila lihat gambar ini! }\end{array}$ & 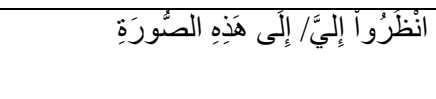 \\
\hline $\begin{array}{l}\text { Sila ambil perhatian pada saya/ } \\
\text { pelajaran! }\end{array}$ & و وا إلَّى الدَّرَسِ \\
\hline Sila buka buku/ buku latihan & 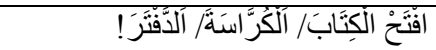 \\
\hline Sila tutup buku/ buku tulis & 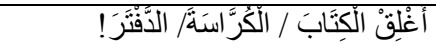 \\
\hline $\begin{array}{l}\text { Harap bersabar wahai/ } \\
\text { Tunggu giliran kamu... }\end{array}$ & اصنْبِرْ يَا ....، انْنَظِرْ دَوْرَكَكَّ \\
\hline $\begin{array}{l}\text { Silakan wahai... lekatkan kad di papan } \\
\text { putih }\end{array}$ & 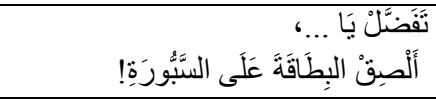 \\
\hline Sila berjalan, jangan berlari... & امْشِ ، وَلَا تَجْرِ! \\
\hline Nyalakan/padamkan lampu! & 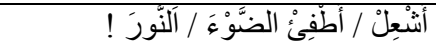 \\
\hline Hidupkan /padamkan kipas/ komputer! & 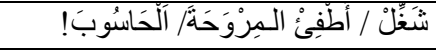 \\
\hline Letakkan buku itu dalam beg/ atas meja! & 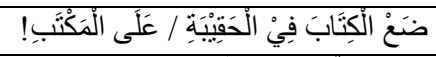 \\
\hline Sila duduk dengan tenang/ sopan & 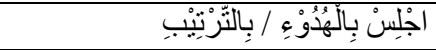 \\
\hline
\end{tabular}




\section{Larangan ( النَّوَاهِيْ )}

\begin{tabular}{|c|c|}
\hline BAHASA MELAYU & اللغة العربية \\
\hline Jangan bercakap dalam kelas! & لَا تَكَكَلْم فِي الْفَصْلِ \\
\hline Jangan bergerak! & 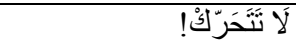 \\
\hline Jangan pergi! & لَا تَذَهَبْ! \\
\hline Jangan lupa! & لَا تَنْسَ / لا تَنْسَسْا! \\
\hline Jangan tidur! & لَا تَنَمُّ \\
\hline Jangan ketawa! & لَا تَضْنَكَكْ! \\
\hline Jangan bermain! & لَانَلَعْبْ! \\
\hline Jangan duduk! & لَا تَجْلِسن! \\
\hline Jangan minum! & لَا تَتَْْرَبْ! \\
\hline Jangan makan dalam kelas! & لَا تَاكَكُلْ فِي الْفَصْلِ \\
\hline Jangan berlari! & لَا نَجْرِ! \\
\hline Jangan tulis! & لَا نَكَتُبْبُ! \\
\hline Jangan buka! & لَالَفْتَحْ! \\
\hline Jangan takut! & لَا تَخَفْ! \\
\hline Jangan kecewa! & لَا تَحْزَنْ! \\
\hline Jangan ambil! & لَالَأَخْنْ.... \\
\hline Jangan berjalan! & لَا تَسَشٍْ! \\
\hline Jangan buang sampah! & لَا تَرْمِ الأوْْسَاخَ \\
\hline
\end{tabular}

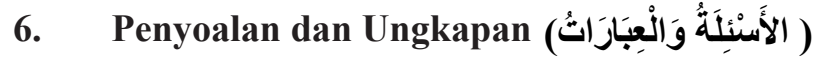

\begin{tabular}{|c|c|}
\hline BAHASA MELAYU & اللغة العربية \\
\hline Siapa nama kamu? & مَا اسْعُكَْْْ \\
\hline Nama saya... & اسنْيْ ...... \\
\hline Adakah kamu seorang pelajar? & 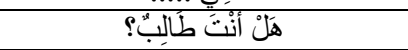 \\
\hline Di mana kamu tinggal? & أَيْنَ تَسْكُكُْْ \\
\hline Saya tinggal di. & 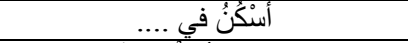 \\
\hline Siapa yang tahu jawapan? & مَنْ يَعْرَفُ الْالِجَابَةُّ \\
\hline Semua sekali.. & $\ldots$ \\
\hline Saya mahu anda semua buat latihan nombor $6 \ldots$ & 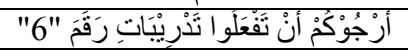 \\
\hline Adakah anda bersedia? & 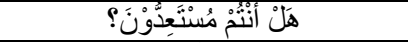 \\
\hline Awas/ Berhati-hati! & 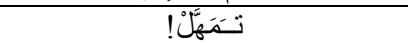 \\
\hline Maafkan saya, apa topik kita sekarang/ hari ini? & 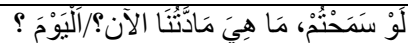 \\
\hline
\end{tabular}




\section{Membetulkan Kesilapan (تَصْحِيْحُ الأَخْطَاءع)}

\begin{tabular}{|c|c|}
\hline BAHASA MELAYU & اللغة العربية \\
\hline Jawapan kamu betul/ tidak betul wahai... & 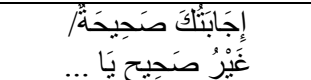 \\
\hline Saya tidak bersetuju dengan kamu wahai... & أنا لَا أوَافِقِكَكَ يَا ... \\
\hline Tidak wahai..., cuba sekali lagi & لَا يَا ...، حَاوِلْ مَرَّةً أَخْرَى \\
\hline Siapa nak bantu dia? & مَنْ بِسَاعِدِهُه/هاب \\
\hline Siapa yang ada idea lain? & مَنْ عِنَدَهُ فِكْرَة أَخْرَى؟ \\
\hline Ada tak jawapan lain? & هَلْ هُنَالَكَ إِجَابَةُ أَخْرَى؟؟ \\
\hline Baca dengan tenang wahai... & 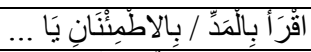 \\
\hline Siapa yang tahu jawapan? & 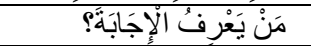 \\
\hline Betul ke salah? & 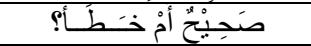 \\
\hline
\end{tabular}

\section{Halangan Guru Menggunakan Lughat al-Faṣl}

Berdasarkan data temu bual yang dijalankan ke atas peserta kajian, halangan yang dinyatakan mereka boleh dibahagikan kepada empat kategori. Kategori pertama adalah tentang personaliti guru itu sendiri dan kedua adalah tentang sikap guru. Halangan yang ketiga pula adalah mengenai kelayakan guru dan yang terakhir adalah berkaitan dengan persekitaran komunikasi bahasa Arab. Dapatan kajian ini mendapati halangan-halangan ini merupakan masalah yang saling berkait di antara satu sama lain. Bermula dengan halangan dari segi personaliti guru, sikap guru, kelayakan guru sehinggalah kepada faktor persekitaran komunikasi seperti yang ditunjukkan pada rajah berikut: 


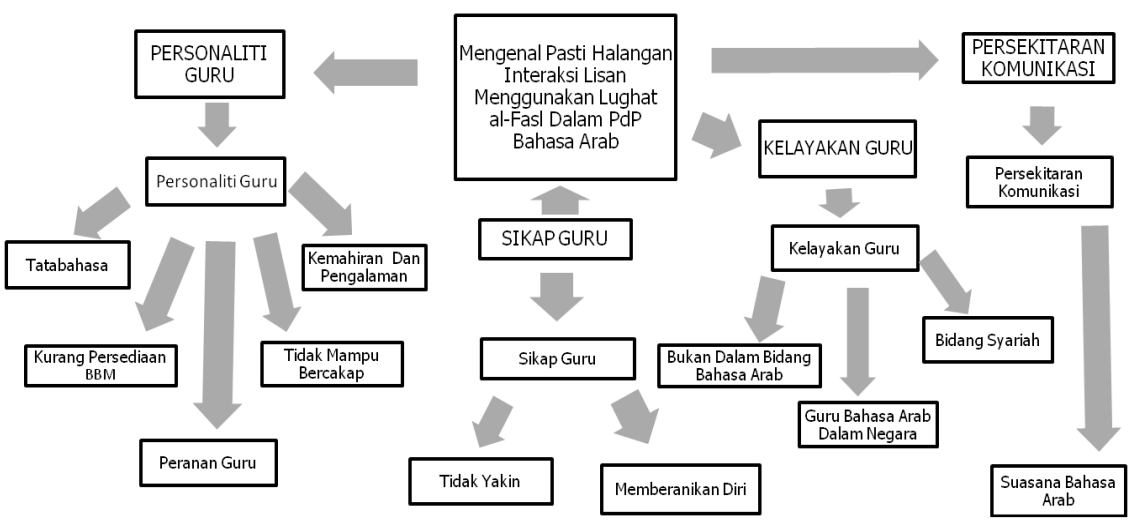

Rajah 1 Halangan guru menggunakan Lughațal-Faṣl

\section{Personaliti Guru}

Personaliti guru memainkan peranan yang sangat penting dalam mewujudkan suasana interaksi PdP yang hidup dan kondusif. Dalam kajian ini, pengkaji telah membahagikan aspek personaliti guru ini kepada lima aspek penting, iaitu peranan guru, tatabahasa, kemahiran dan pengalaman, tidak mampu bercakap dalam bahasa Arab dan kurang persediaan dari segi Bahan Bantu Mengajar (BBM). Hal ini dapat dibuktikan dalam temu bual yang dijalankan dengan peserta kajian:

Dari segi peranan guru dalam kelas, GBA2 menyatakan bahawa guru yang mengajar bahasa Arab perlu berperanan dan aktif berinteraksi dalam kelas. Dalam erti kata lain, guru adalah pilot kepada kelas yang diajar. Berdasarkan temu bual dengan guru, mereka mengatakan:

"Dari segi peranan guru aktif, guru dalam kelas itu dari segi secara fasli, secara jama'ie makna kata perlu berlaku interaksi dua hala..."

P2: TB/GBA2/(PG)-5:3 (23:23)

Berpunca daripada sikap guru yang beranggapan bahawa bahasa Arab dan Lughat al-Fașl adalah sesuatu yang sukar untuk dilaksanakan, ia diabaikan daripada menjadi amalan guru-guru tersebut (Mior Syazril, 2015). Pendapat ini dikongsikan dalam temu bual dengan GBA1 yang bersetuju 
bahawa kesukaran untuk bertutur dalam bahasa Arab menjadi penghalang yang utama dalam pelaksanaan Lughat al-Fașl ini. Ditambah pula dengan kelulusan beliau yang bukan dari bidang Bahasa Arab semasa di universiti.

"Cabaran utama dulu saya rasa saya tak mampu bercakap sebab saya bukan dalam bidang bahasa Arab dan saya bukan belajar dalam bahasa Arab dan mengajar ini kerana tawaran dan bukan saya minta bahasa Arab saya minta Pendidikan Islam dan saya dapat bahasa Arab dan ini cabaran pada diri...”

$$
\text { P1: TB/GBA1/(TMC)-7:5 (19:19) }
$$

Begitu juga dari segi kemahiran dan pengalaman. Pelaksanaan Lughat al-Fașl ini perlu kepada keberanian untuk cuba bertutur dan menimba pengalaman dengan guru lain. Bagi guru yang tidak membiasakan diri akan mengakibatkan guru tersebut kurang latihan, tidak berkeyakinan, takut salah, takut murid tidak faham atau lambat faham yang boleh menjejaskan tempoh masa perancangan guru untuk menghabiskan silibus yang telah ditetapkan.

"Kalau dari guru itu sendiri makna kata persediaan dan juga bahan yang cukup. Dari segi kemahiran dan pengalaman yang dikongsi rakan-rakan lain lah... dari segi persediaan untuk mengajar bahasa Arab dalam LF ini...”

$$
\text { P2: TB/GBA2/(KDP)-5:4 (25:25) }
$$

Akibat tidak membiasakan diri menggunakan bahasa Arab dalam kelas akan menjadikan guru takut atau tidak berani menggunakannya pada masa-masa tertentu apabila diperlukan. Bahkan, ketakutan guru bukan sekadar takut melakukan kesilapan dalam pertuturan dari aspek penggunaan perkataan dan tatabahasa, lebih malang lagi guru juga merasa takut muridmurid tidak dapat memahami apa yang dituturkan oleh guru. Pandangan ini adalah di antara apa yang telah dikatakan oleh GBA2 yang menyatakan bahawa ketakutan melakukan kesilapan dalam tatabahasa Arab ketika bertutur menjadikan guru takut dan terus tidak menggunakannya dalam PdP mereka. Berikut adalah temu bual bersama GBA2:

\footnotetext{
"Ada kadang-kadang tu, dia risau tatabahasa. Ooo penggunaan nahu saraf, sebenarnya untuk bahasa Arab ni dari segi nahu saraf dari segi ucapan ataupun kalam ni senang ja kita matikan ja huruf belakang semua tu jadi tak timbul masalah."
}

P2: TB/GBA2/(TTB)-2:1 (72:73) 
Sebagai seorang guru Bahasa Arab juga, mereka perlu menyediakan sendiri Bahan Bantu Mengajar (BBM) kerana kesukaran untuk mendapatkan BBM dalam bahasa Arab di pasaran. Hal ini juga menjadikan satu lagi penghalang kepada guru untuk menjadikan PdP dalam kelas lebih menarik dan berkesan. Dalam hal ini, GBA1 menyatakan bahawa;

"Saya kurang membuat persediaan BBM bahan bantu mengajar... saya hanya bergantung pada diri saya mula-mula dulu berbanding hari ini, saya dah banyak menyimpan koleksi-koleksi bahan untuk bantu mengajar."

$$
\text { P1: TB/GBA1/(BBM)-1:4 (19:19) }
$$

Sekiranya masalah-masalah pokok ini tidak ditangani, maka amalan Lughat al-Fașl ini akan terus dipandang sepi oleh guru-guru bahasa Arab di Malaysia, khasnya guru-guru bahasa Arab di sekolah rendah.

\section{Sikap Guru}

Setiap tingkah laku, arahan dan aktiviti yang dilakukan oleh guru akan menyumbang kepada suasana pembelajaran di dalam bilik darjah sama ada sebagai positif, negatif atau neutral (Haliza \& Joy, 2014). Guru yang berjaya membina hubungan yang positif dengan murid boleh mencorakkan pengalaman pembelajaran yang menyeronokkan. Dalam konteks pembelajaran bahasa Arab, antara halangan yang dihadapi oleh guru ketika berinteraksi dalam kelas adalah sikap guru itu sendiri. Dalam kajian ini, pengkaji telah mengenal pasti dua aspek yang berkait dengan sikap guru. Pertama, guru tidak yakin kepada diri sendiri untuk menggunakan bahasa Arab di dalam kelas dan kedua, sifat kurang berani menyelubungi diri guru tersebut.

Dalam membicarakan halangan berbentuk sikap yang dimiliki oleh guru itu sendiri, GBA1 telah menyatakan pengalaman beliau sendiri dalam temu bual berikut:

"Cabaran utama dulu saya rasa saya tak mampu bercakap sebab saya bukan dalam bidang bahasa Arab dan saya bukan belajar dalam 
bahasa Arab. Mengajar ini kerana tawaran dan bukan saya minta (opsyen) Bahasa Arab, saya minta Pendidikan Islam dan saya dapat Bahasa Arab dan ini cabaran pada diri saya sendiri tak yakin, rasa tak yakin nak mengajar..."

$$
\text { P1: TB/GBA1/(BD)-7:3 (19:19) }
$$

Melalui temu bual tersebut, beliau menyatakan bahawa pada peringkat permulaan menjadi guru dahulu, beliau berasa sangat tidak yakin untuk mengajar, lebih-lebih lagi untuk mengajar mata pelajaran bahasa Arab kerana beliau bukan berkelulusan bidang bahasa Arab.

Kedua, guru tidak berani untuk mencuba atau memulakan penggunaan Lughat al-Faṣl ketika mengajar. Perkara ini diakui oleh GBA1 melalui pengalaman yang dilalui oleh beliau sendiri:

"Saya telah memulakan penggunaan Lughat al-Faṣl ni bermula pada tahun 2005 secara pemeringkatan... berperingkat sebab 2005 tu baru program j-QAF dilaksanakan, saya memberanikan dirilah atas nasihat dan bimbingan guru praktikum saya untuk mencuba suasana persekitaran penggunaan bahasa Arab supaya murid biasa dengar dan mereka akan belajar untuk faham Lughat al-Faṣl."”

$$
\text { P2: TB/GBA2/(BD)-5:2 (9:9) }
$$

Seterusnya beliau berpendapat bahawa guru bahasa Arab mesti berani mencuba menggunakan Lughat al-Faṣl sepatah demi sepatah walaupun mengalami kesukaran pada peringkat permulaan.

"Nak membiasakan makna kata di kalangan guru bahasa Arab sendiri setidak-tidaknya perlu komunikasi penggunaan bahasa Arab paling tidak celup-celup pun sebagai peringkat mula pun kira kena beranikan diri..."

$$
\text { P2: TB/GBA2/ (BD)-6:2 (71:71) }
$$

Secara umum, terdapat dua cara untuk menjalinkan hubungan guru-murid. Pertama, hubungan perlu dibina sejak hari pertama penggal persekolahan bermula. Guru perlu menarik minat murid ke alam pembelajaran dengan bersikap mesra, mudah didekati tetapi tegas dalam menentukan batas-batas pembelajaran. Kedua, sikap ini perlu kekal sepanjang masa dalam setiap situasi tanpa ada diskriminasi antara murid. 


\section{Kelayakan Guru}

Guru adalah tenaga penting yang menggerakkan pelaksanaan kurikulum Bahasa Arab di sekolah. Oleh itu, keperluan guru yang sesuai merupakan aspek yang mesti diberi penekanan seperti kelayakan, motivasi, keterampilan dan latihan asas guru.

Dari segi kelayakan guru, isu utama yang sering ditimbulkan dalam konteks PdP bahasa Arab adalah kelayakan sijil guru di peringkat Ijazah Sarjana Muda. Keempat-empat peserta kajian dalam kajian ini tidak berkelulusan bidang bahasa Arab, iaitu GBA1 berkelulusan Ijazah Sarjana Muda Perbandingan Agama (UIAM), GBA2 berkelulusan Ijazah Sarjana Muda Syariah (Universiti al-Azhar), GBA3 berkelulusan Ijazah Sarjana Muda Usuluddin (UM) dan GBA4 juga berkelulusan Ijazah Sarjana Muda Syariah (Universiti al-Azhar). Perkara ini dinyatakan oleh GBA1 dalam temu bual yang dijalankan:

“...kira hampir sepuluh tahun dah menjadi guru bahasa Arab dan latar belakang pendidikan saya walaupun saya ni dalam bidang Syariah tapi dari segi penggunaan bahasa Arab itu saya belajar di Universiti al-Azhar di Mesir."

P4: TB/GBA4/(BSY)-5:1 (7:7)

Hal yang hampir serupa disuarakan oleh GBA1 yang berulang kali menyatakan beliau bukan dari bidang Bahasa Arab pernah mengalami kesukaran menggunakan Lughat al-Fașl pada peringkat awal berkhidmat dahulu.

“...sebab saya bukan dalam bidang bahasa Arab dan saya bukan belajar dalam bahasa Arab..."

$$
\text { P1: TB/GBA1/(BBBA)-1:2 (19:19) }
$$

Satu perkara lagi berkenaan kelayakan guru ini dinyatakan oleh GBA2. Beliau menjelaskan bahawa wujud perasaan risau dan rendah diri dalam kalangan sebahagian guru bahasa Arab yang berkelulusan Ijazah Sarjana Muda dalam negara. Apabila mereka melihat sebahagian guru lepasan Timur Tengah yang fasih bertutur dalam bahasa Arab, menjadikan diri mereka terlalu merendah diri sehingga tidak mahu mencuba untuk 
menggunakan bahasa Arab dalam PdP. Situasi sebegini sepatutnya tidak berlaku, malah kedua-dua pihak perlu menggembleng tenaga dan berkongsi pengalaman. GBA2 menyatakan;

"Penggunaan Lughat al-Fașl dalam pengajaran makna kata ianya sesuatu yang harus dikongsi mungkin bagi setiap guru masing-masing ada kelebihan dia tersendiri, kadang-kadang berlaku, saya bukan guru bahasa Arab luar negara saya cuma guru bahasa Arab dalam negara..."

P2: TB/GBA2/(GDN)-6:3. (69:69)

\section{Persekitaran Komunikasi}

Persekitaran asal kepada bahasa Arab adalah sangat membantu dalam penjiwaan komunikasi bahasa Arab. Banyak kajian tentang kepentingan persekitaran pembelajaran murid dalam menguasai sesuatu pembelajaran telah dibuktikan sebelum ini. Kajian yang dijalankan oleh Majdah (2011) mendapati kelemahan murid dalam pembelajaran bahasa Arab adalah berpunca daripada kurangnya amalan dalam mempraktikkan bahasa Arab di rumah mahupun di sekolah. Dari segi halangan persekitaran komunikasi, peserta kajian hanya merujuk kepada satu situasi iaitu suasana bahasa Arab. Perkara ini dianggap sebagai salah satu penghalang yang sering terjadi kepada guru Bahasa Arab di Malaysia ini seperti mana yang disuarakan dalam temu bual dengan GBA2:

"Kalau pada saya untuk murid Tahun Satu sebagai alam baharu kepada murid-murid. Kita mencampurkan sebagai orang kata apa tu... suasana baru untuk permulaan bagi murid cuba untuk memahami, mendekati dan meminati bahasa Arab."

P4: TB/GBA4/(SBA)-4:1 (13:13)

Selain itu juga, lingkungan sosial merupakan salah satu arena atau tempat berinteraksinya seseorang dengan orang lain di sekitarnya. Hasil interaksi dapat menambah pengetahuan seseorang tentang pelbagai perkara seperti dalam berkomunikasi, seseorang dapat belajar tentang bahasa dan tutur kata yang baik dan sesuai digunakan. Sebagai seorang guru bahasa Arab, GBA4 tanpa ragu-ragu mengutarakan pendapat beliau tentang beban tugas yang berat seorang guru dalam mewujudkan suasana bahasa Arab di sekolah bertujuan murid seronok untuk belajar bahasa Arab ini: 
"Jadi kita yang penting dalaman tu seronok kan... yang kedua bina bỉ'ah (suasana persekitaran) maknanya kalau boleh cubalah cakap Arab kan setakat mana yang diorang belajar Lughat al-Faṣl ni..."

P4: TB/GBA4/(SBA)-4:1 (63:63)

Abdul Raof (1998) pula menyatakan persekitaran pembelajaran murid amat penting dalam usaha untuk membentuk pembelajaran murid yang berkesan. Namun, bagi kita di Malaysia yang tidak berada di negara asal penutur bahasa Arab, program pembudayaan berbahasa Arab di peringkat sekolah adalah sangat signifikan dalam usaha menyemai penjiwaan bahasa Arab. Untuk itu, semua guru Bahasa Arab dan Pendidikan Islam mestilah saling bantu membantu dalam usaha mewujudkan persekitaran bahasa Arab yang harmoni. Pendapat ini dapat dilihat melalui temu bual pengkaji dengan GBA2:

"Cuma masing-masing kena ada kesedaran, kena ada keyakinan untuk membawa Lughat al-Fașl ini sebagai kita mewujudkan suasana bahasa Arab dalam kelas terutamanya dalam pembelajaran dan pengajaran bahasa Arab. Jadi makna kata, perkongsian maklumat sesama guru bahasa Arab khususnya, amatlah penting..."

P2: TB/GBA2/(SBA)-2:4 (69:69)

Dalam usaha mewujudkan persekitaran bahasa Arab di sekolah, guru digalakkan memulakannya dengan aktiviti مُمَارَسَةُ الْلْغَة (mempraktikkan bahasa) di dalam kelas menggunakan Lughat al-Faṣl berbentuk pengumuman, arahan, iklan dan makluman. Konsultasi antara guru dan murid juga dilakukan dalam bahasa Arab dan diperluaskan melalui aktiviti laman sosial dengan menggunakan bahasa Arab. Aktiviti-aktiviti yang berbentuk pembudayaan Arab di luar sesi PdP rasmi ini, jika dilakukan secara berterusan mampu membantu murid mahupun guru menjiwai bahasa Arab. GBA2 berpendapat bahawa Lughat al-Faṣl adalah penggerak utama kepada pelaksanaan aktiviti lain sebagai pengukuhan persekitaran bahasa Arab. Beliau berkata:

"Atas nasihat dan bimbingan guru praktikum saya untuk mencuba mengujudkan suasana persekitaran penggunaan bahasa Arab supaya murid biasa dengar dahulu dan mereka akan belajar untuk faham Lughat al-Fașl."

P2: TB/GBA2/(SBA)-2:5 (9:9) 
Justeru, guru boleh mengaplikasi Lughat al-Faṣl semasa PdP bahasa Arab melalui pelbagai aktiviti seperti bertutur dalam bahasa Arab, mendengar pertuturan bahasa Arab rakan, penggunaan bahasa Arab oleh guru, mengemukakan soalan dalam bahasa Arab, perbincangan dalam bahasa Arab, memberi arahan dalam bahasa Arab dan berkomunikasi dalam bahasa Arab.

Langkah-langkah yang boleh diambil oleh guru Bahasa Arab dalam menambah baik penggunaan Lughat al-Faṣl semasa pengajaran bahasa Arab. Berdasarkan objektif pertama dan kedua kajian ini, berikut dicadangkan beberapa langkah yang boleh diambil oleh guru-guru bahasa Arab dalam mengaplikasi Lughat al-Fașl dalam PdP mereka.

Apabila guru mengajar ungkapan baharu Lughat al-Faṣl bahasa Arab, adalah lebih baik untuk mengajar dengan cara yang sama seperti guru mengajar mana-mana perbendaharaan kata baharu. Bermakna, guru perlu menerangkan maksud perkataan yang jelas kepada pelajar, mengaplikasikan ungkapan tersebut dan melihat tindak balas pelajar. Apabila guru menunjukkan pelajar makna ungkapan baharu, guru akan bergantung kepada konteks, pergerakan tangan dan demonstrasi.

Pembelajaran Kontekstual adalah sesuatu yang sangat membantu pengajaran bahasa kedua. Dalam pengajaran bahasa Arab, sesuatu yang paling memberi kesan tentang penggunaan Lughațal-Fașl ialah memulakan setiap pengajaran dengan ucapan selamat dalam bahasa Arab. Sebagai contoh, ungkapan صَبَاحَ الْخَبْرِ , السَّلاًُم عَلَيَكُمْ (Assalamualaikum dan Selamat pagi) atau مَسَاءَ الْخَيْر (Selamat petang),diajar terlebih dahulu di samping pada masa yang sama pelajar turut diajar dan dilatih bagaimana untuk menjawab ungkapan tersebut. Ia akan menjadi jelas dari segi konteks bahawa ungkapan ini adalah salam dan ucap selamat, walaupun guru mungkin perlu menggunakan jam atau lukisan jam untuk mengajar 'pagi' dan 'petang'.

Satu perkara lagi yang sangat penting dalam pengajaran bahasa Arab adalah pergerakan tangan guru. Banyak arahan boleh dibuat secara jelas dengan menggunakan pergerakan tangan. Sebagai contoh, sesetengah pelajar 
suka berdiri pada permulaan pelajaran. Dalam kes ini, guru dengan mudah boleh mengguna dan memperkenalkan arahan تَفَضَّنْ بِالْجُلُوْسِ 'sila duduk!' dengan menggunakan tangan guru untuk menunjukkan bahawa guru mahu pelajar tersebut duduk. Kedua-dua tangan diangkat secara serentak di hadapan murid dan diturunkan beberapa inci ke bawah. Seterusnya, guru juga boleh mengamalkan arahan lain dengan meminta salah seorang pelajar untuk berdiri. Kemudian, guru mengeluarkan arahan dalam bahasa Arab menggunakan pergerakan tangan yang sama, تَفَضَّنْ بِالْجُجُوْسِ '[Nama], sila duduk.'

Satu lagi arahan yang berguna untuk memperkenalkan Lughațal-Faṣl ialah اسنتَمِعُوْْ (sila dengar!). Dengan mudah guru boleh menunjukkannya dengan meletakkan tangan guru di belakang telinga guru. Guru mungkin

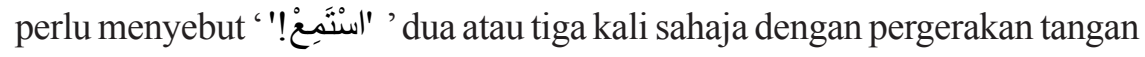
tersebut. Selepas itu, guru tidak perlu lagi membuat pergerakan tangan, memadai dengan menyebut dan kemudian menunggu untuk berdiam diri agar semua pelajar memberi perhatian.

Bagi mengatasi halangan yang berkaitan dengan pelaksanaan Lughat al-Faṣl ini dalam kalangan guru-guru bahasa Arab sekolah rendah, berikut diberikan beberapa cadangan yang boleh dipraktikkan:

1. Guru perlu bersikap positif dan bersedia untuk membuat anjakan paradigma terhadap diri sendiri dalam usaha memajukan diri sendiri dan memantapkan kompetensi tugas guru dalam pengajaran bahasa Arab di sekolah rendah.

2. Guru perlu lebih berani dan bersedia untuk membuat perubahan terhadap persepsi yang mengatakan bahasa Arab adalah bahasa yang sukar untuk dipelajari atau dipraktikkan.

3. Pihak-pihak berkepentingan seperti panitia mata pelajaran bahasa Arab di sekolah, PPD, JPN dan IPGM perlu menyediakan ruang untuk guru membuat latihan mengajar dengan menggunakan bahasa Arab sebagai amalan Lughat al-Fașl. 
4. Latihan dalam perkhidmatan perlu diwujudkan dan dihadiri oleh guru-guru bahasa Arab sekolah rendah dalam memantapkan pedagogi mereka berkenaan pengajaran mata pelajaran bahasa Arab sebagai bahasa asing di Malaysia.

\section{RUMUSAN}

Kajian berkenaan amalan Lughat al-Faṣl dalam PdP bahasa Arab sangat penting untuk diperluaskan dari sudut akademik. Hal ini disebabkan kajian ini boleh menyumbang kepada peningkatan kualiti PdP guru dan murid di sekolah. Amalan Lughat al-Fașl yang baik dan berkesan mampu menghasilkan senario pembelajaran bahasa Arab yang sebenar dan menyeronokkan. Selain itu, ia juga akan menyediakan pengalaman pembelajaran yang akan diingati oleh murid sepanjang hayatnya.

Implikasi kajian ini boleh dilihat dari aspek penggunaan bahasa Arab sepenuhnya sebagai bahasa pengantar di dalam bilik darjah yang lebih baik seandainya guru-guru bahasa Arab sentiasa komited dalam aplikasi Lughat al-Fașl yang terdapat dalam kajian ini. Mungkin ada di antara guru-guru bahasa Arab tidak mengetahui dan tidak mempunyai idea berkenaan ayat atau ungkapan yang perlu dituturkan oleh guru di dalam kelas. Guru sepatutnya menjadikan kelas tersebut sebagai persekitaran sosial dengan mewujudkan situasi penggunaan bahasa yang hampir menyerupai persekitaran sebenar tanpa membuat terjemahan (Muhammad Azhar \& Hassan Basri, 2005).

Penulis berharap agar dengan kajian berkenaan aplikasi Lughat al-Faṣl ini dapat memberikan sedikit panduan khususnya kepada guruguru bahasa Arab sekolah rendah di seluruh negara dalam melaksanakan aktiviti PdP bahasa Arab supaya menggunakan bahasa Arab sepenuhnya melalui medium Lughat al-Faṣl. Di samping itu, diharapkan kajian ini dapat digunakan oleh pihak Kementerian Pelajaran Malaysia untuk mengenal pasti punca masalah sebahagian guru-guru bahasa Arab yang 
tidak dapat berkomunikasi dalam bahasa Arab dengan baik, terutama ketika melaksanakan PdP dalam kelas serta melakukan perancangan yang relevan untuk mengatasi masalah ketidakmampuan guru mengajar bahasa Arab dengan menganjurkan kursus-kursus pemantapan komunikasi bahasa Arab secara berkala, sama ada di dalam negara atau luar negara.

\section{RUJUKAN}

Abdul-Raof, H. (1998). Subject, theme and agent in modern standard Arabic. Psychology Press.

Ahmad Muhammed Ma'tuk. (1996). Al-Hasilat al-Lughawiyyat. Al-Majlis alWataniyy li al-Thaqāfah wa al-Funūn wa al-Adaab. Kuwait.

Bloom, S. (1976). Peer and cross-age tutoring in schools. Washington: National Institute of Education.

Firdaus bt. Abdul Fatah \& Mohd Aminuddin b. Ab. Rahaman. (2014). Tahap penggunaan Lughatul Fasl semasa dalam kalangan guru pelatih j-QAF Opsyen Bahasa Arab. Kertas Kerja Seminar Penyelidikan Pendidikan Zon Tengah.

Gan, Z. (2012). Understanding L2 speaking problems: Implications for ESL Curriculum Development in a Teacher Training Institution in Hong Kong. Australian Journal of Teacher Education.

Haliza Hamzah \& Joy Nesamalar Samuel. (2014). Pengurusan bilik darjah dan tingkah laku. Selangor: Oxford Fajar Sdn. Bhd.

Jefridin Pilus. (2010). Maklum balas guru terhadap respons pelajar semasa pengajaran bahasa Arab tinggi: Satu kajian. Tesis Ph.D. Universiti Kebangsaan Malaysia.

Kementerian Pelajaran Malaysia Pelaksanaan Kurikulum Standard Sekolah Rendah (KSSR) Tahap Satu Mulai 2011. (2010). Putrajaya.

Majdah Mohammad. (2010). Kajian keberkesanan pelaksanaan bahasa Arab komunikasi dalam program j-QAF di sekolah rendah. Disertasi Sarjana Pengajian Islam. Universiti Kebangsaan Malaysia.

Marzano, R. J., Pickering, D., \& Pollock, J. E. (2001). Classroom instruction that works: Research-based strategies for increasing student achievement. Ascd.

Michelle Louwerse. (2001). ELT News.com. The website for English teaching at Japan, http://www.eltnews.com/features/kids_world/2001/06/encouraging classroom_language.html. Retrieved 20 August 2012. 
Miles, M.B \& Hubberman, A. M. (1994). Qualitative data analysis. (2nd Ed.) Beverly Hills, CA. Sage.

Mior Syazril Mohamed Sapawi. (2015). Amalan penggunaan Lughatul-Fasli dalam pengajaran jurulatih utama bahasa Arab Sekolah Rendah. Kertas Projek UKM.

Misnan Jemali. (1999). Hubungan antara gaya pembelajaran dengan pencapaian bahasa Arab komunikasi sekolah menengah rendah di negeri Perak. Tesis Sarjana Fakulti Pendidikan, Universiti Kebangsaan Malaysia.

Mohamad Ziyad \& Saini Ag. Damit. (2015). Amalan penggunaan Lughat al-Fașl dalam kalangan guru bahasa Arab. Prosiding Persidangan Kebangsaan Bahasa Arab (NCAL2015).

Muhammad Azhar Zailani. (2007). Aktiviti komunikatif dalam pengajaran bahasa Arab sekolah menengah. Tesis Ph.D. Fakulti Pendidikan, Universiti Malaya.

Muhammad Azhar \& Hassan Basri. (2005). Aktiviti komunikatif dalam pengajaran bahasa Arab di sekolah menengah: Satu rangka kajian kes. Prosiding 3rd International Qualitative Research Convention 2005, 21-23 Ogos 2005 anjuran Universiti Teknologi Malaysia.

Muhammed Barakāt Hamdi Abu Ali. (1984). Manāhij Wa Arā'F̄̌ Lughat al-Qurān. Ammān: Dār al-Fikr.

Rohaila Yusof, Norasmah Othman \& Faridah Karim. (2005). Strategi Pembelajaran Pengalaman Berasaskan Model Kolb dalam Pendidikan Perakaunan. Jurnal Pendidikan, 30, hlm. 113-128.

Rosni Samah. (2012). Isu pembelajaran bahasa Arab. Persidangan Pengajaran dan Pembelajaran Bahasa Arab. Universiti Kebangsaan Malaysia.

Rosni Samah. (2007). Penggunaan internet dalam pengajaran bahasa: Kajian terhadap bahasa Arab komunikasi pelancongan. Malaysian Education Dean's Council Journal, 1(2), hlm. 83-95.

Rosni Samah. (2009). Pendekatan pembelajaran kemahiran bahasa Arab untuk pelajar bukan penutur jati. Nilai: Penerbit USIM.

Rosni Samah. (2013). Kaedah pengajaran kosa kata bahasa Arab untuk pelajar bukan Arab. Nilai: Universiti Sains Islam Malaysia.

Spindler, G. E. (1982). Doing the ethnography of schooling: Educational anthropology in action. New York: Holt, Rinehart \& Winston.

Spradley, J. P. (1980). Participant observation. New York: Holt, Rinehart \& Winston. 
Sulaiman Md. Yassin, Mohd. Salleh Lebar \& Azlina Abu Bakar. (Pnyt.). (2007). Komunikasi dalam pengajaran dan kepemimpinan pendidikan. Shah Alam: Karisma Publication.

Tanveer, M. (2007). Investigation of the factors that cause language anxiety for ESL/EFL learners in learning speaking skills and the influence it casts on communication in the target language. Master Thesis. University of Glasgow. 
